\title{
Shedding of Herpes Simplex Virus Type 1 into Tears and Saliva in Healthy Japanese Adults
}

\author{
SHIGEAKI OKINAGA \\ Department of Oral Surgery, Kurume University School of Medicine, \\ Kurume 830-0011, Japan
}

\begin{abstract}
Summary: It is well known that asymptomatic viral shedding is one of the forms of reactivation of herpes simplex virus type-1 (HSV-1). Although there have been some long-term investigations of viral shedding into tears and saliva in healthy subjects in the U.S.A, there have previously been no investigation study in Japan. Racial differences in the incidence of reactivation of HSV-1 have been pointed out, and it has been considered that reactivation is found less often among Japanese people than among Westerners. In the present study, we selected 10 healthy adults $(7$ males and 3 females) to isolate HSV-1 from tears and saliva 3 times a week over 6 months, and the results were compared with the results of other studies conducted in the U.S.A. It was found that the virus was isolated in 5 ( 3 males and 2 females) of 10 subjects and of the 5 subjects, the virus was isolated from saliva in 4 and from tears in 1. The number of specimens was 1,742 for tears and 871 for saliva with isolation of 1 and 4, respectively. The duration of shedding was only 1 day in all of the 5 subjects in whom the virus was isolated. The isolation frequency was significantly lower among Japanese people than among American people when our results were compared with the results of studies conducted in the U.S.A. It was clear that the reactivation rate was lower for Japanese people in terms of asymptomatic shedding.
\end{abstract}

Key words herpes simplex virus type 1 , tears, saliva, asymptomatic shedding

\section{INTRODUCTION}

It is empirically known and well established by experiments that HSV-1 stays latently in ganglia following primary infection, and that it becomes reactivated by various factors [1]. However, the mechanism of reactivation has not been elucidated. Reactivation occurs in some people but not in others, and there are also racial differences. According to a questionnaire survey of the history of labial herpes, which is one of the forms involving reactivation, labial herpes was seen more frequently in white people than in non-white people, and seen in American people more frequently than in Japanese people [2,3]. Furthermore, HSV-1 isolation from the trigeminal ganglion in autopsy revealed that virus was isolated more often from American cadavers than Japanese cadavers, suggesting the presence of racial differences [3]. However, there have been no studies of asymptomatic viral shedding into tears and saliva, which is another form of reactivation, except for some reports of investigations of American people [4-7]. In Japan, there are only reports by Kameyama et al. [8], who reported on virus shedding into saliva during 2 months of observation. But their results can not be compared with Americans studies at the same level. Because the duration of observation was short, the age of the subjects were different, and isolation from tears was not performed.

In the present study, we selected healthy adults and isolated HSV-1 from tears and saliva collected from the subjects over 6 months to elucidate whether there are also racial differences between American people and Japanese people in asymptomatic shed- 
ding into tears and saliva.

\section{MATERIALS AND METHODS}

Ten healthy adults with HSV-1 antibodies (7 males and 3 females) were selected for the study. The age ranged from 22 to 62 years with a mean age of 38.6 years (Table 1). Tears from the two eyes and saliva were collected every Monday, Wednesday, and Friday between Oct. 1997 and Mar. 1998. Tears were collected by swabbing the inferior palpebral conjunctiva with a sterile glass rod, and saliva was collected by swabbing the floor of the mouth with a sterile periostial elevator. Each specimen was put in to a different test tube containing stock solution (phosphate buffer solution containing $4 \%$ bovine serum). All samples were stored at $-80{ }^{\circ} \mathrm{C}$. The subjects were asked about their general health, presence of labial herpes, presence of keratitis, and presence of menstruation (for females) at the time of specimen collections.

\section{Cells}

Cells derived from Human embryonic lung (HEL) and from Africa green monkey kidney (GMK) were grown in Eagle's minimal essenntial medium (MEM) supplemented with 10\% bovine serum. HEL was used for the isolation of virus and GMK was used for the assay of virus and for antibody titration.

\section{Isolation of virus}

Specimens were thawed from $-80{ }^{\circ} \mathrm{C}$ and centrifuged at 3,000 rpm for $10 \mathrm{~min}$. One milliliter of the

TABLE 1.

Subjects studied

\begin{tabular}{ccccc}
\hline Subject & Sex & Age & $\begin{array}{l}\text { Presence of } \\
\text { history of labial } \\
\text { and corneal herpes }\end{array}$ & $\begin{array}{l}\text { Neutralizing } \\
\text { antibody titer }\end{array}$ \\
\hline A & F & 22 & $(+)$ & $\times 160$ \\
B & M & 26 & $(-)$ & $\times 320$ \\
C & M & 27 & $(-)$ & $\times 160$ \\
D & F & 27 & $(+)$ & $\times 320$ \\
E & M & 32 & $(+)$ & $\times 160$ \\
F & M & 38 & $(+)$ & $\times 320$ \\
G & M & 52 & $(-)$ & $\times 640$ \\
H & M & 59 & $(+)$ & $\times 640$ \\
I & F & 59 & $(+)$ & $\times 640$ \\
J & M & 62 & $(+)$ & $\times 640$ \\
\hline
\end{tabular}

supernatant was inoculated onto HEL cells and incubated at room temperature in a stationary rack for $2 \mathrm{hrs}$. Fresh MEM supplemented with $2 \%$ bovine serum was added after the inoculum was discarded. The cultures were incubated at $37{ }^{\circ} \mathrm{C}$ and checked for cytopathic effect (CPE) every day for 1 week. When CPE characteristic for HSV was observed, the culture was frozen. The isolated virus was grown once more in GMK cells and stored at $-80{ }^{\circ} \mathrm{C}$.

\section{$H S V$-type specificity}

Samples showing CPE were tested for HSV-1 or 2 type specificity by using a neutralization assay with guinea-pig antisera specific for HSV-1 and 2. Tenfold serially diluted virus samples were mixed with equal volumes $(0.5 \mathrm{ml})$ of HSV-1 (at a dilution of 1:25) or HSV-2 (1:70) specific antisera. After $1 \mathrm{hr}$ incubation at $37{ }^{\circ} \mathrm{C}$, the mixture was plated onto GMK cells from the identification of type specificity.

\section{Serum antibody to $H S V-1$}

Serum from each individual was examined for HSV-1 neutralizing antibody titer by a plaque assay. Heat-inactivated serum was serially diluted from $1: 10$ to $1: 640 ; 0.5 \mathrm{ml}$ diluted serum was mixed with $0.5 \mathrm{ml} \mathrm{HSV}-1$ suspension (HSV-1 strain $\mathrm{YH}$ ) containing 1,000 PFU/ml. After $1 \mathrm{hr}$ of incubation at 37 ${ }^{\circ} \mathrm{C}$, the mixture was plated onto a GMK monolayer culture. After 4 days of incubation at $37{ }^{\circ} \mathrm{C}$, cells were strained with crystal violet and plaques were counted. The highest dilution of serum which reduced plaque formation by $50 \%$ was taken to be the neutralizing antibody titer.

\section{RESULTS}

The virus was isolated in 5 of 10 subjects $(\mathrm{A}, \mathrm{B}$, E, G, I) (Fig. 1), and the isolation rate was $50 \%$. The 5 subjects consisted of 3 males and 2 females. Virus was isolated from saliva in 4 subjects and from tears in 1 subject. The total number of the specimens collected was 1,742 for tears and 871 for saliva. The viral isolation strains was 1 of 1,742 for tears and 4 of 871 for saliva. The duration of shedding was 1 day for all strains that showed viral isolation. The onset of labial herpes was noted once in Subject A and Subject $\mathrm{E}$ during the experiment. However, the virus was not isolated from tears or saliva in either subject during the onset of the disease, but was isolated from saliva 8 weeks before in Subject A and 3 weeks after in Subject E. The onset of corneal herpes was not noted. In the subjects from whom viral isolation was 


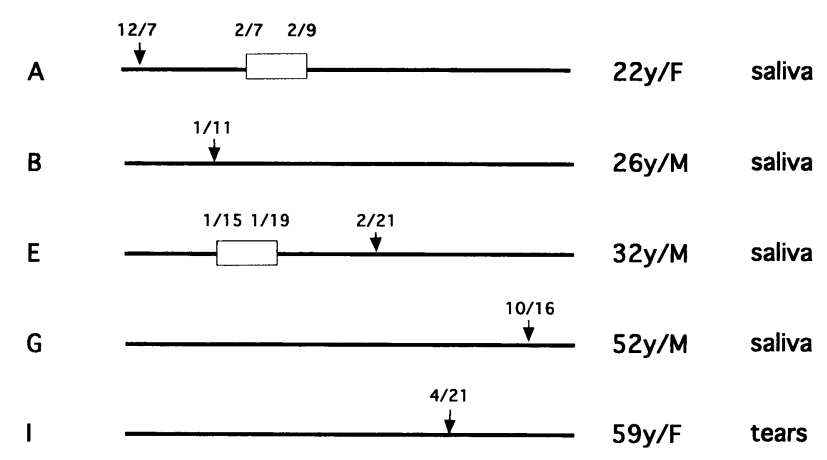

Fig. 1. Times of shedding of HSV-1 in saliva or tears and durations of herpes labialis.

$$
\downarrow \text { HSV isolation labial herpes }
$$

from tears, the virus was not isolated from saliva, and the onset of labial herpes was not noted during the experiment. As a result of inquiry about general health, presence of labial herpes, presence of keratitis, and presence of menstruation, it was found that these conditions were not related to the time of viral isolation in any subject. HSV-type specificity of all isolated viruses was found to be HSV-1.

\section{DISCUSSION}

It is well established that reactivation occurs during latent infection with HSV-1, presenting as an onset of labial herpes and herpes mucosae $[9,10]$, or as asymptomatic shedding of the virus into tears and saliva. Various factors have previously been listed empirically as the causative factors of reactivation, and these factors have already been supported by experiments [11-18]. Based on these results, Openshaw et al. [1] concluded that reactivation of latent viruses is attributable to the injuries of the nerve roots and peripheral nerves as well as to a decrease in the immunocompetence of the host. Reactivation does not necessarily occur in every patient, and reactivation does not always occur with the same stimulus.

Racial differences in reactivation of HSV-1 have previously been pointed out [2,3]. Embil et al. [2] conducted a questionnaire survey about the onset of labial herpes, selecting 10,000 university or college students in 6 continents. It was shown in the study that the onset of labial herpes was noted in many white people from North America, Europe and Australia, and was noted in fewer non-white people from Asia and South America. The incidence of labial herpes was compared between American people and Asian people, and the incidence was $42 \%$ for American males and $37 \%$ for American females, but $19 \%$ for Asian males and $17 \%$ for Asian females. There was therefore a significant differnce between American people and Asian people. Warren et al. [3] conducted a questionnaire survey about labial herpes by selecting 146 American adults and 245 Japanese adults, and the incidence was $35.6 \%$ for American adults, but $24 \%$ for Japanese adults. The viral isolation rate was also compared between American adults and Japanese adults after performing explant culture of the trigeminal ganglion removed in autopsy. It was shown that reactivation was noted in 22 of 44 American cadavers (50\%), but was noted in 7 of 29 Japanese cadavers (24\%), revealing that the rate was significantly lower for Japanese. When compared by the number of removed trigeminal ganglions, reactivation was noted in 30 of 85 ganglia (35\%) for American cadavers, and in 7 of 52 ganglia (13\%) for Japanese cadavers, showing a racial difference in the rate of reactivation of latent viruses. Warren et al. [3] inferred that these racial differences may result from fewer opportunities of HSV-1 infection or higher resistance against HSV-1 among Japanese people. According to Budding et al. [19], when age distribution of subjects with HSV-1 antibodies was examined, people without HSV-1 antibodies accounted for 4 to $10 \%$ of people of aged 15 years and above in America, showing that almost all people had acquired antibodies in their childhood. However, according to the serological epidemiological study conducted by Wentworth et al. [20], people without HSV-1 antibodies accounted for $75 \%$ of people aged 14 years and above and $43 \%$ of people in their 30's and 40's, revealing an increase in the age of people with antibodies. Similarly, McDonald et al. [21] in Canada reported that people without HSV-1 antibodies accounted for $65 \%$ of people aged between 2 and 15 years. According to a study of people of the similar age conducted by Hondo [22] in Japan, people without HSV-1 antibodies accounted for $20-26 \%$ of people in their 20 's and 30's, showing that there are fewer people without these antibodies in Japan than in America. Thus, the inference report by Warren et al. [23], also showed that HSV-1 stayed latently not only in the trigeminal ganglion but also in the superior cervical lymph nodes and ganglion of the vagus nerve, and inferred that there may be differences in the site of latent infection for Japanese people. However, there has as 
TABLE 2.

Previous reports of HSV-1 shedding into saliva and tears in healthy adults

\begin{tabular}{lcccc}
\hline \multicolumn{1}{c}{ Authors } & $\begin{array}{c}\text { Number and age } \\
\text { of subjects }\end{array}$ & $\begin{array}{l}\text { Times and durations of } \\
\text { specimens collected }\end{array}$ & $\begin{array}{l}\text { Frequency of shedding of } \\
\text { HSV-1 into saliva }\end{array}$ & $\begin{array}{l}\text { Frequency of shedding of } \\
\text { HSV-1 into tears }\end{array}$ \\
\hline Kaufman et al $^{4)}(1967)$ & 35 & $5 /$ week/20days & $9 / 699(12 \%)$ & $11 / 1400(0.8 \%)$ \\
Douglas et al $^{5)}(1970)$ & $10(24-48 \mathrm{y})$ & $3 / \mathrm{week} / 5 \mathrm{mo}$ & $11 / 494(2.2 \%)$ & - \\
Spruance et al $^{6)}(1984)$ & $8(25-55 \mathrm{y})$ & $5 /$ week/5mo & $36 / 580(6.2 \%)$ & - \\
Kaye et al $^{7)}(1990)$ & $24(19-69 \mathrm{y})$ & $3 / \mathrm{week} / 4 \mathrm{mo}$ & $10 / 752(1.33 \%)$ & $0 / 752$ \\
Okinaga et al $(1997)$ & $10(22-62 \mathrm{y})$ & $3 / \mathrm{week} / 6 \mathrm{mo}$ & $4 / 871(0.45 \%)$ & $1 / 1742(0.05 \%)$ \\
\hline
\end{tabular}

No. of positive strain / total specimens collected

yet been no report in Japan discussing the site of latent infection among sensory ganglions except for the trigeminal ganglion, and there is too little information to draw a conclusion.

Among signs of reactivation of latent viruses is asymptomatic shedding of viruses into tears and saliva. The majority of studies of asymptomatic viral shedding were conducted in the U.S.A., and the results of the studies conducted in the U.S.A. that included healthy people are summarized in Table 2 . The only report in Japan that concerned itself with asymptomatic shedding is the one by Kameyama et al. [10], but there are some problems in this report. Namely, the duration of the investigation was only 2 months, the age of healthy subjects ranged invariably, and isolation from tears was not performed. In the present study, we aimed to examine whether there is a difference in the asymptomatic shedding into saliva and tears in healthy adults between American people and Japanese people. Ten healthy adults were selected, and isolation of HSV-1 was performed three times a week over 6 months. The results were compared with those of the previous studies on American people. It was found that virus was isolated in 5 of 10 subjects, and all of the 5 subjects showed asymptomatic shedding, which was noted in only one day. Shedding was noted in saliva in 4 subjects and in tears in 1 subject. The isolation rate was $0.45 \%$ ( 4 of 871 ) for saliva, which was relatively low. This rate was compared with the results of the studies by Douglas et al. [5], Spruance [6], and Kaye et al. [7]. Although there was no significant difference from the report by Kaye et al., the rate was significantly lower than that described in the report by Douglas et al. $(\mathrm{p}<0.005)$ and that described in the report by Spruance $(\mathrm{p}<0.001)$. In addition, viral isolation during the previous week and following week of the onset of disease was eliminated from the data in the reports in the U.S.A., and if this was also included in the data, the reactivation rate would be higher. Isolation from tears was performed by Kaufman et al. [4] and Kaye et al. [7], and viral isolation was noted in 11 of 1,400 specimens $(0.8 \%)$ according to the report by Kaufman et al. However, viral isolation from tears was not noted in the report by Kaye et al. Because of the paucity of information, no clear comparison was possible concerning shedding into tears. As for asymptomatic shedding into saliva, although the cells used and the method of specimen collection differed between the two races, there were significant differences in the rate of shedding between American people and Japanese people. This supports the results by Embil et al. [2] and Warren et al. [3]. The reason for this racial difference has not been elucidated, but it is of interest to speculate from the study by Embil et al., which revealed that the incidence was low among non-white people in Asia and Africa, that melanocytes may be relevant. What is interesting is that viruses are shed more often into saliva than tears. As shown in Table 2, the study by Kaufman et al. is in agreement with ours. In a series of studies, we have previously reported viral isolation from saliva collected from patients undergoing various types of surgery and examined how stimulation in the peripheral nerve affects reactivation of HSV-1. In an early paper of the series of studies, Kusukawa [24] isolated HSV-1 from tears and saliva collected from patients undergoing ophthalmic surgery and oral surgery for one week after surgery, and compared the results. It was found that viral isolation was noted in 56 of 918 specimens (6.1\%) collected from patients undergoing oral surgery while viral isolation was noted in 29 of 1,161 specimens $(2.4 \%)$ collected 
from patients undergoing ophthalmic surgery, revealing that the incidence was significantly lower for those undergoing ophthalmic surgery $(\mathrm{p}<0.01)$. Even when the data were analyzed separately for tears and saliva, the incidence was lower for both tears and saliva in patients undergoing ophthalmic surgery. Whether these findings are attributable to the difference in the location of latent infection or portal of entry remains to be determined.

ACKNOWLEDGMENTS: The author wishes to thank Prof. Tadamitsu Kameyama, Department of Oral Surgery, for his helpful advice and suggestions in preparing this manuscript. This work was supported in part by a Grant-in-Aid for Scientific Research from the Ministry of Education, Science and Culture of Japan.

\section{REFERENCES}

1. Openshaw H, Sekizawa T, Cantin E, Puga A, and Notokins AL. Latency and reactivation of herpes simplex virus. In: Viral Infections in Oral Medicine, ed. Hook Jordan JW, Elsevier, New York/North-Holland, pp79-88, 1982.

2. Embil JA, Stephens RG, and Manuel FR. Prevalence of recurrent herpes labialis and aphthous ulcers among young adults in six continents. Can Med Assoc J 1975; 113:627-630.

3. Warren KG, Wroblewska Z, Okabe H, Brown SM, Gilden GH et al. Virology and histopathology of the trigeminalganglia of Americans and Japanese. Can J Neurol-Sci 1978; 5:425-430.

4. Kaufman HE, and Broun DC. Recurrent herpes in rabbit and man. Science 1967; 156:1628-1629.

5. Douglas RG Jr, and Couch RB. A prospective study of chronic herpes simplex virus infection and recurrent hrepes labialis in humans. J Gen Virol 1970; 33:547-550.

6. Spruance SL. Pathogenesis of herpes simplex labialis: Excretion of virus in the oral cavity. J Clin Microbiol 1984; 19:675-679.

7. Kaye MD, and McCarthy P. Ocular shedding of herpes simplex virus. Br J Ophthalmol 1990; 74:111-116.

8. Kameyama T, Sujaku C, Yamamoto S, Hwang CBC, and Shillitoe EJ. Shedding of herpes simplex virus type 1 into saliva. J Oral Pathol Med 1985; 17:478-481.

9. Weathers DR, and Griffin JW. Intraoral ulcerations of recurrent herpes simplex and recurrent aphthae: two distinct clinical entities. J Am Dent Assoc 1970; 81:81-85.
10. Kameyama T, Murase H, Haikata K, Nakamura $Y$, Futami $\mathrm{M}$ et al. The clinico-virological evaluation of recurrent intraoral herpes simplex virus infection. J Jpn Stomatrol Soc 1987; 36:69-77.

11. Underwood GE, and Weed SD. Recurrent cutaneous herpes simplex in hairless mice. Infect Immun 1974; 10:471-474.

12. Walz MA, Price RW, and Notkins AL. Latent ganglionic infection with herpes simplex virus type 1 and 2: Virus reactivation in vivo after neuroectomy. Science 1974; 184:1185-1187.

13. Stevens JG, Cook ML, and Jordan MC. Reactivation of latent herpes simplex virus after pneumococcal pneumonia in mice. Infect Immun 1975; 12:162-165.

14. Scrriba M. Herpes simplex virus infection in guinea pigs: an animal model for studying latent and recurrent herpes simplex virus infection. Infect Immun 1975; 12:162-165.

15. Blyth WA, Hill JT, Field HJ, and Harbour DA. Reactivation of herpes simplex virus infection by ultraviolet light and possible involvement of prostaglandins. J Gen Virol 1976; 33:547-550.

16. Hill TJ, Blyth WA, and Harbour DA. Trauma to skin causes recurrence of herpes simplex in the mouse. J Gen Virol 1978; 39:21-28.

17. Kurata T, Kurata K, and Aoyama Y. Reactivation of herpes simplex virus (type 2) infection in trigeminal ganglia and oral lips with cyclophosphamide treatment. Jpn J Exp Med 1978; 48:427-435.

18. Openshaw H, Asher LV, Wohlenberg C, Sekizawa T, and Notkins AL. Acute and latent herpes simplex virus ganglionic infection: Immune control and vial reactivation. J Gen Virol 1979; 44:205-215.

19. Budding GJ, Schrum DI, Lanier JC, and Guidry DJ. Studies of the natural history of herpes simplex infection. Pediatrics 1953; 11:595-609.

20. Wentworth BB, and Alexander ER. Seroepidemiology of infections due to members of the herpes virus group. Am J Epidemiol 1971; 94:496-507.

21. McDonald AD, Williams MC, West R, and Stewart J. Neutralizing antibodies to herpes virus type 1 and 2 in Montreal women. Am J Epidemiol 1974; 100:124-129.

22. Hondo R. A seroepidemiological study of herpes simplex virus. Jpn J Med Sci Biol 1974; 27:205-213.

23. Warren KG, Brown SM, Wroblewska Z, Gilden D, Koprowski $\mathrm{H}$ et al. Isolation of latent herpes simplex virus from the superior cervical and vagus ganglions of human being. New Eng J Med 1978; 298:1068-1069.

24. Kusukawa R. Clinico-virological study for shedding of herpes simplex virus type 1 into the saliva and tears. J Kurume Med Assoc 1993; 56:669-681. (in Japanese) 